\title{
Iniquidades de gênero: mulheres com HIV/Aids em situação de violência
}

| ${ }^{1}$ Roger Flores Ceccon, ${ }^{2}$ Stela Nazareth Meneghel |

Resumo: Este estudo tem como objetivo visibilizar as iniquidades de gênero presentes na vida de mulheres com HIV/aids em situação de violência. Estudo qualitativo que utilizou narrativas de 61 mulheres cadastradas no Serviço de Assistência Especializada em HIV/aids de um município de médio porte do interior do Rio Grande do Sul, sendo utilizada a técnica de análise de narrativa para a compreensão dos dados. Foi construída uma narrativa única a partir da percepção dos pesquisadores e das trajetórias de vida das entrevistadas, contemplando aspectos vivenciados pela maioria delas. A maior parte das mulheres era jovem, pobre, ocupava empregos precários e muitas exerceram a prostituição ao longo da vida. As mulheres se constituem como figuras do sofrimento e são tratadas pela sociedade como promíscuas, infratoras e "putas". Houve relatos de violências, abusos, preconceitos, estigmas, infraçôes de direitos e sofrimentos. As desigualdades de raça, classe social e gênero são situaçôes geradoras de vulnerabilidades, violências e iniquidades na vida de mulheres com HIV/aids.

> Palavras-chave: gênero; iniquidade; violência contra a mulher; HIV; aids.

\footnotetext{
${ }^{1}$ Universidade Federal do Rio Grande do Sul. Porto AlegreRS, Brasil (roger.ceccon@ hotmail.com).

2 Universidade Federal do Rio Grande do Sul. Porto Alegre-RS, Brasil (stelameneghel@gmail. com).
}

Recebido em: 12/04/2017 Aprovado em: 31/10/2017 


\section{Introdução}

Este artigo busca compreender os efeitos produzidos pelas iniquidades na vida de mulheres com HIV/aids em situação de violência, sendo utilizada a categoria gênero como ferramenta analítica para entender os processos sociais e as relaçóes de poder que incidem sobre as mulheres, o que implica assumir que o corpo funciona como território de identidades e alvo de hierarquia social. As identidades femininas resultam de discursos ideológicos que formatam modelos, papéis e estereótipos, em que a mulher é socialmente subalternizada em sociedades patriarcais (MEYER, 2009; SCOTT, 1990).

A teoria do patriarcado considera que um dos mecanismos de legitimaçáo social da desigualdade entre homens e mulheres é a socialização de gênero, por meio do qual as mulheres sáo educadas e aprisionadas ao script da função social de esposas e máes, o que é considerado parâmetro da conduta feminina. A socializaçáo de gênero mascara a hierarquia entre os sexos e a dominaçáo masculina, para os quais as mulheres devem serviços e obediência de acordo com o contrato sexual do casamento. Este contrato pressupóe que no contexto conjugal o sexo é um direito dos maridos e uma obrigação feminina (SANTOS; IRIART, 2007; COYLE et al., 2011; PATEMAN, 1996; SAGOT, 1995).

Nas últimas décadas, apesar de avanços importantes na legislação relativa à proteção das mulheres e na formulação de políticas públicas femininas, ainda não foi possível obter igualdade na garantia de direitos em relação aos homens. As desigualdades evitáveis e injustas entre os sexos impedem o acesso a recursos materiais e simbólicos para as mulheres, configurando iniquidades de gênero, que as colocam em situação de vulnerabilidade a agravos e doenças (UNAIDS, 2005).

A vulnerabilidade é compreendida como o nível de suscetibilidade a doenças ou agravos a que as mulheres estáo expostas e a disponibilidade de recursos que possuem para se proteger. Consideram-se três dimensôes da vulnerabilidade, que se relacionam para constituir a especificidade de uma situação em saúde, podendose destacar a dimensão individual, onde são reconhecidos os acontecimentos nocivos à saúde, as trajetórias pessoais das mulheres e suas condiçóes materiais e psicossociais; a dimensão social, na qual se analisam cenários socioculturais e de proteção dos direitos humanos; e pela dimensão programática, que compreende as políticas e serviços dos diferentes setores da sociedade (AYRES et al., 2003; AYRES; PAIVA; BUCHALLA, 2012). Um dos princípios da compreensão do 
processo de saúde-doença com base no quadro da vulnerabilidade é a identificação

de situaçóes de infraçóes relativas aos direitos humanos. Em territórios ou segmentos populacionais onde há violaçōes de direitos, encontra-se também maior frequência de doenças e mortes, inclusive por aids e violências perpetradas contra mulheres (AYRES; PAIVA; FRANÇA JUNIOR, 2012).

A epidemia de HIV/aids e a violência de gênero são problemas sociais de elevada magnitude no Brasil, tendo ocorrido aumento da incidência entre populações pobres, em municípios do interior do país e entre o sexo feminino. Ainda que todas as mulheres sejam suscetíveis à violência e à aquisição do HIV/ aids, há maior vulnerabilidade em alguns grupos, principalmente entre jovens, negras e pobres. ${ }^{1}$

Viver com HIV/aids e sofrer violências é uma violação de direitos humanos das mulheres e, embora este fenômeno ainda seja pouco visibilizado, constitui uma forma de controle e/ou punição às que não cumprem os papéis de gênero designados pela cultura patriarcal. Estudos observaram elevadas prevalências de violências em mulheres com HIV/aids no Brasil, visto que $72 \%$ das que vivem com a doença relataram ter sofrido violência de gênero: 63\% psicológica, $52 \%$ física e $28 \%$ sexual. As violências físicas e sexuais, geralmente coexistentes, corresponderam a mais da metade dos casos (BARROS; SCHRAIBER.; FRANÇA-JUNIOR, 2011; CECCON; MENEGHEL, 2015; CECCON; MENEGHEL; HIRAKATA, 2014).

Mulheres com HIV/aids são consideradas pela sociedade como infratoras, promíscuas, impuras, marcadas com a condição de risco e segregadas a espaços restritos. A elevada prevalência de violências neste grupo, o fato de sofrerem preconceitos, estigma, culpabilização e serem tratadas com iniquidade nos serviços resulta da moral sexual baseada em normas sobre o que é o comportamento sexual adequado e, como se trata de condiçóes associadas aos "desviantes", as mulheres com HIV/aids aceitam o rechaço social e acreditam que a doença é uma punição merecida. Dessa forma, é necessário conhecer os contextos sociais e trajetórias de vida das mulheres com HIV/aids para a formulação de políticas públicas de proteção específicas a este grupo, incluindo especificidades que as vulnerabilizam. ${ }^{2}$

O sistema patriarcal, capitalista e racista produz práticas cotidianas de dominação e exploração feminina, produzindo exclusões e iniquidades que afetam principalmente mulheres que vivem com HIV/aids, fato ainda pouco 
explorado na literatura (BRILHANTE et al., 2016). Este estudo tem como objetivo visibilizar as iniquidades de gênero presentes na vida de mulheres com HIV/aids em situação de violência.

\section{Percurso metodológico}

Este é um estudo qualitativo que utilizou narrativas de mulheres com HIV/ aids, buscando explorar suas trajetórias de vida marcadas por violências de gênero. Para a compreensão dos dados da pesquisa, foi usado o referencial teórico-metodológico do construcionismo social, que compreende as narrativas como ferramentas capazes de produzir explicaçóes para a realidade vivida pelas mulheres, pois possibilitam lembrar acontecimentos e compreender situaçóes que permeiam a vida individual e social (LARROSA, 1995; INIIGUEZ, 2004). As trajetórias de vida foram conhecidas por meio de relato oral em entrevistas abertas, entendidas como um conjunto de eventos que fundamentam a vida das mulheres, determinadas pela frequência, duração e localização dos acontecimentos, além de mudanças sociais que ocorreram em suas vidas, situação econômica, atividades profissionais e outras vivências singulares (BORN, 2001).

A coleta de dados foi realizada no ano de 2013 no Serviço de Assistência Especializada em HIV/aids (SAE) de um município de médio porte do interior do Rio Grande do Sul, que ocupava o quinto lugar entre as cidades brasileiras em casos de HIV/aids (BRASIL, 2014). A escolha pelo local considerou a elevada incidência da doença (82 casos/100 mil habitantes em 2010) e a acentuada feminização da epidemia (incidência em mulheres passou de 16/100 mil no ano 2000 para 61/100 mil em 2012). Participaram da pesquisa todas as mulheres com idade superior a 18 anos, que sofriam violência de gênero, viviam com HIV/ aids e estavam cadastradas no SAE, perfazendo um total de 61. Foram ouvidos relatos espontâneos sobre suas vidas marcadas pelo HIV/aids e pelas violências.

As mulheres foram convidadas a participar da pesquisa e, se aceitassem, eram informadas sobre o contexto da investigação e os procedimentos da entrevista. A questão disparadora para a produção da narrativa era: "Conte sua vida e fale sobre as violências que sofreu." As mulheres entrevistadas não foram interrompidas durante a narração, e no final foram feitas perguntas complementares sobre situações que precisavam ser mais detalhadas. Elas relataram suas vidas e trajetórias, usando geralmente o tempo cronológico para organizar a narrativa. 
Para a análise e compreensão dos relatos, utilizou-se a análise de narrativa, que procura entender as falas, conversas e rememoraçóes de falantes a partir da narração de suas vivências. Esta análise compreende o discurso narrativo como prática social constitutiva da realidade e os modos como os atores sociais constroem explicações e entendimentos para suas próprias vivências (RIESSMAN, 2008). A partir dos relatos das mulheres, foi construída uma narrativa única que focou as iniquidades de gênero vivenciadas por elas, utilizando fragmentos das narrativas que contemplaram aspectos vividos pela maioria. ${ }^{3}$

\section{Resultados e discussão: "Tenho nojo de homem"}

As situaçôes de violências e iniquidades de gênero marcaram as histórias de vida de todas as mulheres que viviam com HIV/aids entrevistadas neste estudo. Realizou-se uma síntese dos fatos e significados atribuídos pelas mulheres às suas trajetórias de vida, compondo uma construção coletiva que envolveu a interface narradora-pesquisadores.

Os resultados do estudo produzidos a partir da construção coletiva foram apresentados em uma história única, pois se observou similaridade nos contextos, cenários e experiências vividas pelas mulheres. Entre os resultados deste estudo, destaca-se que a maioria das mulheres era jovem, pobre, precisou ocupar empregos precários e muitas exerceram a prostituição. Houve relatos de violências, abusos, infraçôes de direito em todas as etapas da vida e as dores e sofrimentos se repetiam, com diferentes nuances e detalhes. Para relatar estas histórias sob a perspectiva das iniquidades devidas a gênero ou ao fato de serem mulheres, foi construída a narrativa denominada "tenho nojo de homem", que foi produzida a partir da costura tecida entre as trajetórias de vida das entrevistadas e a percepção dos pesquisadores. Esta narrativa irá sendo contada aos poucos, intercalando os fatos relatados com a discussão e referencial teórico.

A história mostra o quanto as mulheres com HIV/aids se constituem como figuras do sofrimento e de como são tratadas pela sociedade, que as consideram promíscuas, infratoras e "putas". Tenho nojo de homem é o desabafo repetido na narrativa de uma delas, como resposta subliminar à violência exercida em sociedades patriarcais. Esta violência atravessa a vida dessas mulheres, presente no abuso sexual de crianças e adolescentes, na saída de casa para deixar de ser um encargo econômico, na necessidade de fazer sexo por dinheiro ou por 

homens familiares, amigos, namorados, clientes e maridos, culminando com a aquisição da aids.

\section{O primeiro homem que tive nojo}

Não lembro quase nada da minha infância, mas acho que foi nela que comecei a pegar
nojo de homem. Minha mãe sempre disse que eu precisava encontrar um homem
bom pra casar. Fui encarando isso como natural. Tudo mudou depois que soube que
meu pai tinha amante. Minha mãe saía pra trabalhar e ele levava a vizinha pra dentro
de casa. Um dia cheguei mais cedo do colégio e os dois estavam na cama da mãe.
Contei tudo, mas ela acabou perdoando. Eu não podia acreditar naquilo. Depois
disso minha vida virou um inferno. Meu pai começou a me agredir. Me batia por
qualquer motivo e bebia sem parar. Tudo isso porque estava apaixonado pela vizinha.
Perdeu a cabeça. Também passou a agredir minha máe. Até que um dia, bêbado,
me expulsou de casa. Mas antes me derrubou, me chutou e me bateu com um cinto.
Mesmo chorando, antes de ir, consegui cuspir na cara dele. Era o primeiro homem
que eu pegava nojo.

Conforme observado, as mulheres entrevistadas neste estudo sofreram desde a infância um tratamento marcado pela falta de cuidado, negligência e violências, percebidas mesmo quando suas narrativas náo revelaram a real dimensão das infrações de direitos cometidas contra elas. Elas percorreram itinerários de vida que se iniciam com a socialização de gênero quando meninas, que as expuseram à subordinação desde a infância, continuando na adolescência com a busca de um companheiro e uma relação de conjugalidade como saída para abusos, trabalho infantil e violência familiar.

As mulheres que ouvimos exerceram ao longo da vida papéis designados ao feminino em sociedades patriarcais. $\mathrm{O}$ discurso que veicula o desempenho desses papéis é reflexo da "ideologia de gênero", que impóe a normatizaçáo, naturalizada socialmente, de como deve ser o comportamento esperado para cada sexo. $\mathrm{O}$ conceito de ideologia de gênero refere-se à concepção marxista e compreende a falsa consciência na qual a realidade é modificada a favor dos dominantes. Tem a função de manter as hierarquias entre os sexos, objetivando a dominação das mulheres, com o intuito de mascarar a desigualdade de poder entre dominadores e dominados, sendo, portanto, uma forma de consciência parcial, ilusória e enganadora (LOWY, 1985).

Os padróes sociais vigentes nas pequenas cidades do interior do Rio Grande do Sul, como a localidade onde foi realizado o estudo, assim como em outras regióes 
brasileiras, ainda são os de sociedades de honra, com estrita divisão sexual dos

papeis. Assim, as mulheres entrevistadas estão circunscritas ao espaço doméstico, ao casamento e ao cuidado de filhos. Foi comum a expulsáo de casa quando apresentaram alguma conduta considerada não aceitável ou quando constituíram um encargo econômico à família.

Percebeu-se, nos relatos, o quanto está vigente a educação diferenciada segundo o sexo, parte da socialização de gênero, que normatiza segundo a régua do patriarcado quais os valores, papéis e atribuiçôes serão designadas e aceitas para cada um dos sexos. Portanto, nas sociedades do interior do Rio Grande do Sul, mesclam-se noçôes tradicionais de sociedades de honra com valores urbanos veiculados pelas mídias, em que hierarquias se mantêm travestidas de modernidade, propalando uma pretensa liberdade sexual feminina, já que as mulheres continuam subordinadas ao desejo masculino de com quem, como e de que maneira serão as relaçôes sexuais. Essa ideologia irá onerar e oprimir as mulheres, acrescentando às mais vulneráveis o ônus da doença, fato evidenciado pelas elevadas prevalências de HIV/aids em mulheres e pelo ranking no cenário brasileiro do município em estudo (TRAVERSO-YÉPEZ; PINHEIRO, 2005).

\section{O segundo homem que peguei nojo}

[...] Fui morar na casa de uma tia. Devia ter uns 10 anos. No começo foi tranquilo, mas depois acabei virando empregada. Ela dizia que eu tinha que pagar a estadia. Fazia todo o serviço de casa e cuidava dos filhos dela. Tive que largar o colégio. Foi lá também que sofri meu primeiro estupro. Eu tava em casa e meu primo, que era uns 10 anos mais velho, me convidou pra ir brincar na casa dele, só que eu achei que a tia tava em casa. Quando chegamos não tinha ninguém. Me assustei, fui sair e ele me puxou pra dentro, me arrastou pro quarto pelos cabelos. Eu tinha uns 10 e ele 20 anos. Eu chorava, tentava chutar, esperneava. Ele tirou minha bermuda e minha calcinha. Fiquei machucada e roxa, com os braços doloridos. Ele falou que era brincadeira e eu nunca contei pra ninguém. Fiquei envergonhada. Achei que a culpa era minha. Foi o segundo homem que peguei nojo.

Neste estudo, as jovens não possuíam autonomia para refutar relacionamentos abusivos, não percebiam suas vulnerabilidades e muitas vezes não conseguiam negar relaçóes sexuais indesejadas. A educação diferenciada de gênero faz com que as meninas se sintam lisonjeadas com o desejo do "outro" e muitas vezes se sintam obrigadas a fazer sexo para agradar ao parceiro. Desta maneira, 
muitas fazem sexo sem conhecer, dispor e/ou utilizar preservativos, e a mesma sociedade que não as protege e viola seus direitos humanos, usando condutas que propugnam passividade e permissividade aos desejos masculinos, imputa a elas a responsabilidade, a culpa e o desprezo pelo sexo não consentido, pela gravidez precoce e pela aquisição do HIV/aids (HEILBORN, 2003).

Em sociedades tradicionais, como as do interior do Rio Grande do Sul, as normas para o comportamento sexual feminino permanecem mais rígidas do que nas metrópoles brasileiras. Ainda pode estar vigente a exigência da virgindade antes do casamento, muitas vezes confundida com inocência e ignorância de questóes sexuais, além de passividade, falta de reconhecimento ou expressão de desejo, obrigação de satisfazer o parceiro, fidelidade sexual e reprodução de filhos como o objetivo do sexo e do casamento.

Aos homens, em contrapartida, espera-se que tenham vida sexual ativa, relaçóes sexuais com muitas mulheres, amplo conhecimento das questóes referentes ao sexo, impulso sexual incontrolável, além de mostrar força, invulnerabilidade e agressividade. Esse padrão constitui um obstáculo para a prevenção do HIV/aids, pois alienam e desautorizam as mulheres - que precisam mostrar-se sexualmente ingênuas - a usar ações e práticas de prevenção. Além do mais, traz riscos também aos homens, que não se veem como potencialmente propensos à aquisição do vírus, mesmo quando não se protegem (CAMPBELL, 2007).

\section{$\mathrm{Na}$ “zona”: outra vez sentindo nojo}

[...] Depois disso fiquei mais um tempo na minha tia e fui morar com uma amiga num quartinho no centro. Devia ter uns 16 anos. Ela recebia clientes que pagavam pra fazer sexo. Logo entrei na onda. Cobrava barato, eu era bonitinha e todos os dias tinha um ou outro. Briguei com essa amiga e fui parar na zona. Foi horrível, mas eu precisava me sustentar. Mal sabia ler, ia trabalhar onde? Pior que o dono da casa batia. Quando o cliente chegava, não tinha direito de dizer "não". Se ele gostasse de ti, se ele te pagasse bebida, tinha que subir pro quarto. A maior parte do dinheiro do programa ficava pro dono da casa, e no final da noite ele escolhia uma ou duas que davam pra ele de graça. Todas tinham que transar com ele. Era norma da casa. Nunca usei camisinha com ninguém. Até queria. Tentava colocar, fazia um boquete pra ajeitar e eles davam um jeitinho e tiravam. Ou arrebentavam. Ficava só aquela borrachinha de cima. Fiquei na zona por um tempo curto. Não era pra mim aquela vida. Acho que não deve ser pra nenhuma daquelas. Todas que eu conversava estavam ali por obrigação. Nenhuma dizia que gostava de fazer aquilo. Que desse prazer e tal. Tinham histórias muito tristes. 
Iletradas ou com pouca educação formal e qualificação para o trabalho, muitas mulheres entrevistadas encontraram na prostituição o único recurso para garantir o sustento mínimo para sobreviver. Dentre os fatores que levam as mulheres que ouvimos a se prostituir estão a pobreza, os abusos familiares, gestaçôes sem recursos em sociedades tradicionais e a falta de redes de apoio social e financeiro. Como referido por Carcedo (2010), atualmente o mercado do sexo e da exploração sexual é um dos setores mais lucrativos mundialmente. Neste mercado, as prostitutas recebem o status de objetos sexuais, que podem ser facilmente descartados quando adoecem, se rebelam ou envelhecem e é mantido continuamente pela entrada de jovens pobres, de etnias minoritárias, migrantes e oriundas de países em guerra ou conflitos bélicos, onde são alvo do tráfico de pessoas, drogas e exploração sexual comercial. O exercício da prostituição é, na maioria das vezes, realizado em territórios onde vigora a lei do mais forte e da violência, onde imperam gangues, traficantes, cafetôes, gigolôs e michês, que submetem as mulheres a violências, abusos e exploraçóes. A sociedade patriarcal ainda separa as mulheres entre "putas" e "mães de família”, e as que exercem prostituição constituem um grupo marginalizado e estigmatizado. Na medida em que os usuários pagam pelo sexo, sentem-se no direito de usar o corpo pago conforme seus desejos, fazendo-os objetos de violência e até mesmo de morte, além de ocasionar risco elevado de contrair HIV/aids, visto que muitos homens rejeitam o uso do preservativo ou o retiram durante a prática sexual (LIPSZYC, 2003).

\title{
Amava e tinha nojo do marido
}

\begin{abstract}
[...] Logo casei. Fiquei casada 23 anos e infeliz. Ele tinha amantes, saía até com homem. Eu descobria e logo perdoava. Era a sina da minha mãe. De tanto que critiquei eu estava passando pela mesma situação. Ele saía e ficava dias sem aparecer em casa. Engravidou outra mulher, teve que pagar pensão. Tudo isso casado comigo. Mas eu era apaixonada por ele, por muitos anos eu fiquei assim. Depois ele começou a ficar agressivo, me xingava, e logo começou a me dar tapa na cabeça, na cara, me pegava pelo pescoço. Aquilo foi me deixando sem saber o que fazer. Naquela época eu não entendia nada, achava que tinha que viver aquilo pra sempre. Foram 23 anos assim.
\end{abstract}

Conforme observado neste estudo, as mulheres tendem a ignorar ou aceitar passivamente as múltiplas parcerias sexuais do companheiro, femininas ou masculinas. A bissexualidade masculina, às vezes negada pelo próprio homem, faz com que eles - que não revelam suas preferências sexuais - vivenciem práticas homossexuais em segredo, mantendo uma imagem heterossexual. Este fato 
decorre da heterossexualidade compulsória imputada pela sociedade, sendo que a bissexualidade masculina não reconhecida aumenta o risco do HIV/aids, pois ao não assumir sua preferência sexual, os homens passam a frequentar estabelecimentos clandestinos e relacionar-se sem a devida proteção (ANDREFF, 2001).

A socialização de gênero constrói as mulheres para serem subordinadas ao homem, considerado provedor, a figura que sustenta a família e detém o pátrio poder, papel acentuado nas classes sociais mais pobres. É um processo que cumpre funçóes de controle e objetiva adaptar as pessoas às normas sociais estruturadas com base na desigualdade de gênero. Essa forma de organização social patriarcal aceita apenas o papel da mulher submissa, mãe e esposa dedicada. Resulta de um processo de domesticação para torná-la responsável pela casa, pela família, pelo casamento e procriação, cuja imagem está ligada a atributos ditos femininos: passividade, recato e domesticidade. Assim, o espaço privado, apesar das palavras de ordem do feminismo de que "o pessoal é político", continua sendo o lócus das mulheres, obrigadas pelos códigos de silêncio a manter sigilo do que ocorre "entre quatro paredes”. A essas relações sobrevêm filhos, rupturas e novos parceiros, sempre na esperança alicerçada nos mitos românticos de encontrar o par ideal (BARKER; LOWENSTEIN, 1997).

As mulheres são vítimas da falta de autonomia na condução da vida sexual e reprodutiva. O homem é quem decide o uso do preservativo e onde, quando e como serão as práticas sexuais, situaçáo que aumenta a vulnerabilidade das mulheres à aquisição do HIV/aids, visto que retira a autonomia sobre seu corpo e sexualidade, além de aumentar o risco de violência, utilizada para reforçar a dominação masculina (ANDREFF, 2001; HEBLING; GUIMARÃES, 2004).

\section{As pessoas tinham nojo de mim}

[...] Mas até que um dia ele colocou um revólver na minha cabeça. Disse que ia me matar, que não me aguentava mais. Aí deu, era demais. Eu precisava ter um pingo de amor próprio. Resolvi me separar. A última relação sexual que ele me forçou eu falei: "Não, eu não quero mais! Eu sinto ódio por ti, não quero nem que me toque". Fugi e deixei casa, filho. Tudo. Ele veio atrás. Na primeira vez eu voltei. A gente vivia na mesma casa e em camas separadas. Só que naquele tempo a doença já estava incubada e a gente não sabia. Fiz o exame aqui no SAE e deu positivo. Ele pegou na rua e me passou. Caímos os dois doentes. Ele dizia que fui eu quem passou pra ele. Me culpava. Todo mundo me culpava. Eu me culpava. Nem mais me importava. As pessoas tinham nojo de mim. 
Neste estudo, a maioria das mulheres enfrenta dificuldades na revelação do HIV/aids e prefere ocultar a doença para não sofrer preconceitos e discriminaçóes, sendo culpabilizadas inclusive pelos homens que as contaminaram. Mesmo quando o vírus foi transmitido pelo parceiro, recai sob a mulher a culpa e a responsabilidade, pois a relação conjugal é instituída pela desigualdade de gênero. O diagnóstico do HIV/aids para algumas mulheres é uma declaração de morte; para outras, "nem mais importa".

O diagnóstico da doença afeta as perspectivas de vida que foram construídas pelas mulheres, pois o que prevalece é a ideia de finitude rápida e o medo da morte. Além do mais, o diagnóstico positivo provoca intenso temor, angústia e sofrimento, porque a doença agudiza fragilidades nas questôes relacionadas à sexualidade, à vida e à morte. No imaginário social, anuncia um castigo, um atestado de óbito prematuro ou uma sentença de morte (SALDANHA, FIGUEIREDO, 2002).

O estigma é produzido em função dos modos de transmissão e das normas sociais preexistentes à epidemia, referidas à prescrição de comportamentos com base em estereótipos de gênero e na normatização da sexualidade. Como assinalado por Parker (2002), a transmissão sexual da aids é considerada uma tragédia, já que é uma doença envolta em moralismos, e adquiri-la significa ser alvo de censura que não é dirigida a outras doenças. As pessoas que apresentam a infecção percebem-se muitas vezes como "pecadoras", o que gera sentimento de culpa, ódio de si mesmas, rejeição, autoagressão, medo, ansiedade, depressão, raiva e suicídio.

Nas narrativas que ouvimos, muitas se sentiam culpadas pela contaminação e estavam revoltadas consigo mesmas por não terem se cuidado, embora diante da irreversibilidade do ato, continuavam se negligenciando. Outro sentimento que apareceu é o da raiva em relação ao companheiro, que as infectou e à sociedade que as colocou em situaçóes de tal precariedade e vulnerabilidade que trouxe a doença como consequência.

Preconceito, discriminação, culpa e estigma difundidos pela sociedade às mulheres com HIV/aids limitam a possibilidade da revelação, fazendo com que guardem em segredo o status sorológico, o que dificulta a construçáo de redes de apoio e ajuda mútua. Além do mais, a revelação ao companheiro, mesmo que ele seja o transmissor do vírus, pode gerar violência e culpabilização da mulher, acusando-a de infidelidade e promiscuidade (RENESTO et al., 2014). 
[...] Não conseguia ver ele sofrendo daquele jeito. Eu já tinha me levantado. Estava bem. Acabei voltando pra ele. Precisava ajudar pra ele sair dessa. Cuidei dele até a morte. Tenho saudade. Ano passado tentei me matar. Cortei os pulsos com faca. Não consigo emprego, sou pobre e estou sem dinheiro. Hoje não tenho ninguém. Minha vida acabou. Sigo sentindo nojo de homens.

Neste estudo, muitas mulheres cuidaram de maridos ou companheiros com os quais tiveram uma vida de violências, outros que as infectaram e negavam que lhes transmitiram a doença, e ainda os que as abandonaram e voltaram no fim da vida para serem cuidados por elas. Sabe-se que um dos papéis de gênero atribuídos às mulheres é o cuidado do outro, demonstrando afeto e compaixão, mesmo em se tratando de pessoas que as abusaram e violentaram (LESSA, 2012).

Nas 61 narrativas que ouvimos, os itinerários de vida e as estratégias de resistência se deram no contexto da violência e dominação masculina. As opções que as mulheres possuem para enfrentar os abusos são poucas, pois as mesmas estáo sob a tutela masculina em todos os âmbitos da sociedade. Umas encontraram "proteção" no casamento e outras na prostituição, embora todas precisem "pagar" com os corpos, com a disponibilidade sexual irrestrita e com os serviços domésticos.

Ao longo da vida, no casamento, em relaçóes amorosas ou na prostituição, as mulheres são dominadas, oprimidas e violentadas por homens. São pais, padrastos, cafetóes, clientes, namorados e maridos que exercem poder sobre os corpos femininos. Muitas vezes são os mesmos que lhes transmitem o vírus HIV em relações moldadas por desigualdades de gênero. A construção social da necessidade de as mulheres estarem sob a tutela masculina dificulta o rompimento das situaçóes abusivas, tanto de mulheres casadas quanto das que exercem prostituição, uma vez que estas estão sempre "devendo" favores aos homens que as protegem no casamento ou na prostituição.

\section{Considerações finais}

As mulheres entrevistadas neste estudo sofreram iniquidades ao longo da vida, cumprindo papeis ditados pela cultura, o que Simone de Beauvoir chamou de "destino de gênero", em que o valor e o mérito está relacionado ao quanto produzem, servem e cuidam, embora também tenham transgredido as normas sociais para garantir a sobrevivência. Algumas mulheres necessitaram de recursos 
econômicos do homem com o qual casaram, viveram, cuidaram e/ou serviram; outras possuíam independência financeira mas também se comportaram de acordo com os papéis de gênero. Como cuidadoras, são exploradas pelo sistema capitalista, já que o trabalho com o cuidado faz parte de um mercado gratuito realizado majoritariamente por mulheres, em que as relaçóes de dominação são naturalizadas e subestimadas.

As trajetórias de vida das mulheres foram marcadas por desigualdades de gênero, vulnerabilidades, iniquidades e violação de direitos humanos, impulsionadas pelas normas regulatórias de gênero e pelos processos de estigmatização ao HIV/ aids. Dentre as dimensóes individuais, sociais e programáticas da vulnerabilidade vivenciada por essas mulheres, pode-se concluir que na infância elas não tiveram cuidado e proteção adequados e foram vítimas de negligência e violências; na adolescência, não conseguiram evitar relacionamentos abusivos e negar relaçôes sexuais indesejadas. $\mathrm{Na}$ vida adulta, sofreram com a falta de educação formal e qualificação para o trabalho, e buscaram segurança na prostituição ou em casamentos, nos quais precisaram conviver com as infidelidades e violências. Descoberto o vírus HIV, elas enfrentaram dificuldades na revelação do diagnóstico, ocultaram a doença para não sofrer preconceitos, discriminações e culpabilização. Por fim, cuidaram de maridos adoecidos pela aids que as infectaram e as maltrataram ao longo da vida.

As mulheres entrevistadas estão aprisionadas em uma sociedade de controle, subjetivadas por meio da cartilha do patriarcado, enredadas em relaçôes de poder desiguais, cimentadas pela ideologia machista que incide sobre suas mentes e corpos. Enquanto persistirem os padróes patriarcais que balizam a socialização dos homens e mulheres na sociedade, pouco se poderá fazer para romper com as discriminaçóes e iniquidades, já que estas derivam de hierarquias de poder e concepções estereotipadas das feminilidades e masculinidades. As mulheres deste estudo, pela inserção precária na sociedade, moldada pelas desigualdades de raça, classe social e gênero, foram reduzidas a vidas descartáveis, sem direito ou garantia de serem protegidas. ${ }^{4}$

\section{Referências}

ANDREFF, W. Evénementiel sportif, impact économique et régulation. In: DESBORDES, M.; RICHELIEU, A. Néomarketing du sport, Regards croisés entre Europe et Amérique du Nord. Bruxelles: Boeck, 2001. 
AYRES, J. R. C. M. et al. O conceito de vulnerabilidade e as práticas de saúde: novas perspectivas e desafios. In: CZERESNIA, D.; FREITAS, C. M. (Org.). Promoção da saúde: conceitos, reflexôes, tendências. Rio de Janeiro: Fiocruz, 2003. p. 117-139.

AYRES, J. R. C. M. Sujeito, intersubjetividade e práticas de saúde. Cienc. Saúde Colet. Rio de Janeiro, v. 1, n. 6, p. 63-72, 2001.

AYRES, J. R. C. M.; PAIVA, V.; BUCHALLA, C. M. Direitos Humanos e vulnerabilidade na prevenção e promoção da saúde: uma introdução. In: PAIVA, V.; AYRES, J. R. C. M.; BUCHALLA, C. M. (Orgs.). Vulnerabilidade e direitos humanos: prevenção e promoção da saúde. Livro I. Curitiba: Juruá Editora, 2012. p. 9-22.

AYRES, J. R. C. M.; PAIVA, V.; FRANÇA, I. Conceitos e práticas de prevenção: da história natural da doença ao quadro da vulnerabilidade e direitos humanos. In: PAIVA, V.; AYRES, J. R.; BUCHALLA, C. M. (Org.). Direitos humanos e vulnerabilidade na prevenção e promoção da saúde [Coletânea]. Livro 1: Da doença à cidadania. Curitiba: Juruá, 2012. p. 71-94.

BARKER, G.; LOWENSTEIN, I. Where the boys are: attitudes related to masculinity, fatherhood and violence towards women among low income adolescent and young adult males in Rio de Janeiro, Brazil. Youth \& Society. Michigan, v. 29, n. 2, p. 166-196, 1997.

BARROS, C. R. S.; SCHRAIBER, L. B.; FRANÇA-JUNIOR, I. Associação entre violência por parceiro íntimo contra a mulher e infecção por HIV. Rev. de Saúde Publica. São Paulo, v. 45, n. 2, p. 365-732, 2011.

BORN, C. Gênero, trajetória de vida e biografia: desafios metodológicos e resultados empíricos. Sociologias. Porto Alegre, v. 1, n. 5, p. 240-265, 2001.

BRASIL. Ministério da Saúde. Boletim Epidemiológico HIV-AIDS. Brasília, ano III, n. 1, 2014.

BRILHANTE, A. V. M. et al . Um estudo bibliométrico sobre a violência de gênero. Saude soc. São Paulo, v. 25, n. 3, p. 703-715, 2016.

CAMPBELL, T. Poverty as a violation of Human Rights: Inhumanity or Injustice? In: POGGE, T. (Ed.). Freedom from poverty as a human right: Who owes what to the very poor? Oxford: Oxford University Press, 2007. p. 15-30.

CARCEDO, A. No ouvidamos ni aceptamos: Feminicídio em Centro América 200-2006. 1. ed. San José: Asociación Centro Feminista de Información y Acción, 2010.

CECCON, R.F.; MENEGHEL, S.N. HIV e violência contra mulheres: estudo em município com alta prevalência de Aids no Sul do Brasil. Revista Panamericana de Salud Publica. Washington, v. 37, n. 4/5, 2015.

CECCON, R. F; MENEGHEL, S. N.; HIRAKATA, V. N. Mulheres que vivem com HIV: violência de gênero e ideação suicida. Revista de Saúde Pública. São Paulo, v. 48, n. 5, p. 758-765, 2014.

COYLE, K. et al. R. Safer choices: reducing teen pregnancy, HIV, and STDs. Public Health Report. Washington, v. 116, n. 1, p. 82-93, 2011. 
DEVRIES, K. et al. Violence against women is strongly associated with suicide attempts: evidence from the WHO multi-country study on women's health and domestic violence against women. Social Science Medicine. London, v. 73, n. 1, p. 79-86, 2011.

GARCIA-MORENO, C. et al. Prevalence of intimate partner violence: findings from the WHO multi-country study on women's health and domestic violence. Lancet. London, v. 368, n. 9543, p. 1260-1269, 2006.

HARLING, G.; TSAI, A. C.; SUBRAMANIAN, S. V. Intimate partner violence and HIV: embracing complexity. Lancet Global Health. London, v. 3, n. 6, p. 313, 2015.

HATCHER, A. M. et al. Intimate partner violence and engagement in HIV care and treatment among women: a systematic review and meta-analysis. AIDS. London, v. 29, n. 16, p. 2183-2194, 2015.

HAYES, N. C.”Dying is dying, that's all": Structural violence and cultural projects in Malawian AIDS proverbs. Africa Journal AIDS Resarch. Grahamstown, v. 14, n. 3, p. 229-237, 2015.

HEBLING, E. M.; GUIMARÃES, I. R. F. Women and AIDS: gender relations and condom use with steady partners. Cadernos de Saúde Pública. Rio de Janeiro, v. 20, n. 5, p. 1211-1218, 2004.

HEILBORN, M. L. Articulando gênero, sexo e sexualidade: diferenças na saúde. In: GOLDENBERG, P.; MARSIGLIA, R.M.G.; MARA, H.A.G. (Org.). O clássico e o novo: tendências, objetos e abordagens em ciências sociais e saúde. 1. ed. Rio de Janeiro: Fiocruz, 2003. p. 197-208.

IÑIGUEZ, L. Análisis del discurso. Manual para las ciencias sociales. 2. ed. Barcelona: Editorial UOC, 2004.

LARROSA, J. Déjame que te cuente: ensayos sobre narrative y educación. 2. ed. Barcelona: Laertes, 1995.

LESSA, S. Abaixo à família monogâmica! 2. ed. São Paulo: Instituto Lukács, 2012.

LIPSZYC, C. Prostitución o esclavitud sexual? 2. ed. Lima: CLADEM, 2003.

LOWY, M. Ideologia e ciência social: elementos para uma análise marxista. 1. ed. São Paulo: Cortez, 1985.

MEYER, D. Corpo, violência e educação: uma abordagem de gênero. In: JUNQUEIRA, R. D. Diversidade sexual na educação: problematizaçôes sobre a homofobia nas escolas. 1. ed. Brasília: Ministério da Educação, 2009. p. 213-234.

MOHAMMADI, N.; KOCHAK, H. E.; GHARACHEH, M. The lived experience of domestic violence in Iranian HIV-infected women. Global Journal Health Science. Canada, v. 7, n. 5, p. 43-50, 2015.

OKAREH, O. T. et al. Management of conflicts arising from disclosure of HIV status among married women in southwest Nigeria. Health Care Women International. Washington, v. 36, n. 2, p. 149-60, 2015. 
PARKER, R. The Global HIV/AIDS pandemic, structural inequalities, and the politics of international health. Am. J. Public Health. New York, v. 92, n. 3, p. 343-347, 2002.

PATEMAN, C. Críticas feministas a la dicotomía público/privado. In: CASTELLS, C. Perspectivas feministas en teoría política. 1. ed. Barcelona: Paidós, 1996.

RENESTO, H. M. F. et al. Enfrentamento e percepção da mulher em relação à infecção pelo HIV. Revista de Saúde Pública. São Paulo, v. 48, n. 1, p. 36-42, 2014.

RIESSMAN, C. K. Narrative methods for the human sciences. 2. ed. California: Sage, 2008. SAGOT, M. Socialización de género, violencia y femicidio. Revista Reflexiones. Costa Rica, v. 41, n. 1, p. 17-26, 1995.

SALDANHA, A. A. W.; FIGUEIREDO, M. A. C. Gênero, relaçóes afetivas e aids no cotidiano da mulher soropositiva. In: SIDANET ASSOCIAÇÃO LUSÓFONA. O HIV no mundo lusófono. 1. ed. Santarém: Normagrafe, 2002. p. 35-47.

SANTOS, C. O.; IRIART, J. A. B. Significados e práticas associados ao risco de contrair HIV nos roteiros sexuais de mulheres de um bairro popular de Salvador, Bahia, Brasil. Cad. Saúde Pública. Rio de Janeiro, v. 23, n. 12, p. 2896-2905, 2007.

SANTOS, N. J. S. et al. Contextos de vulnerabilidade para o HIV entre mulheres brasileiras. Cad. Saúde Pública. Rio de Janeiro, v. 25, n. sup. 2, p. 321-332, 2009.

SCHRAIBER, L. B.; BARROS, C. R. S.; CASTILHO, E. A. Violência contra as mulheres por parceiros íntimos: usos de serviços de saúde. Revista Brasileira de Epidemiologia. São Paulo, v. 13, n. 2, p. 237-45, 2010.

SCOTT, J. W. Gênero: uma categoria útil de análise histórica. Educação \& Realidade. Porto Alegre, v. 20, n. 2, p. 1-35, 1990.

TRAVERSO-YÉPEZ, M. A.; PINHEIRO, V. S. Socialização de gênero e adolescência. Revista Estudos Feministas. Florianópolis, v. 13, n. 1, 2005.

UNAIDS. AIDS: epidemic up date. 1. ed. London: UNAIDS/WHO, 2005.

\section{Notas}

${ }^{1}$ Cf. Hatcher et al. (2015); Barros, Schraiber e França-Junior (2011); Ceccon e Meneghel (2015); Ceccon, Meneghel e Hirakata (2014); Devries et al. (2011); Garcia-Moreno et al. (2006); e Hayes (2015).

${ }^{2}$ Cf. Harling, Tsai e Subramanian (2015); Mohammadi, Kochak e Gharacheh (2015); Santos et al. (2009); Okareh et al. (2015); Schraiber, Barros e Castilho (2010); Parker (2002); e Ayres (2001).

${ }^{3}$ Esta pesquisa respeitou as recomendaçôes da Declaração de Helsinque e foi conduzida segundo a resolução específica do Conselho Nacional de Saúde (número 196/96). O estudo é recorte da tese de doutorado apresentada ao Programa de Pós-Graduação em Enfermagem da Universidade Federal do Rio Grande do Sul. O projeto foi aprovado pela Comissão de Pesquisa da Escola de Enfermagem e pelo Comitê de Ética e Pesquisa da Universidade Federal do Rio Grande do Sul sob o número 22209.

${ }^{4}$ R. F. Ceccon e S. N. Meneghel participaram igualmente da concepçâo, delineamento, análise e interpretação dos dados; redação do artigo e sua revisão crítica; e aprovação da versão a ser publicada. 
Gender inequities: women with HIV/Sida in situation of violence

This study aims to make visible the gender inequities in the lives of women with HIV/SIDA in situations of violence. A qualitative study that used the narratives of 61 women enrolled in the Service of Specialized Care in HIV/SIDA of a medium-sized municipality in an inland area of Rio Grande do Sul state, Brazil, using the technique of narrative analysis to understand the data. A unique narrative was built based on the researchers' perceptions and the life trajectories of the interviewees, contemplating aspects experienced by most of them. Most women were young, poor, employed in precarious employment, and many practiced prostitution throughout their lives. Women constitute themselves as figures of suffering and are treated by society as promiscuous, abusive and "whores". There were reports of violence, abuses, prejudices, stigma, violations of rights and suffering. Inequities of race, social class and gender are situations that generate vulnerabilities, violence and inequities in the lives of women with HIV/SIDA.

> Keywords: gender; iniquity; violence against women; HIV; Aids. 